\title{
Salivary Amylase as Potential Biochemical Marker in Diabetes Mellitus
}

\author{
${ }^{1}$ BNVS Satish, ${ }^{2}$ Prashant Kumar, ${ }^{3} \mathrm{SM}$ Avanti, ${ }^{4}$ Shruti Singh
}

\begin{abstract}
Introduction: Diabetes mellitus has emerged as a major global health problem. Diagnosing and monitoring diabetes is the best way for its prevention, thus reducing the burden of disease. As saliva is easily available and accessible when compared with serum, salivary biomarkers have gained importance in recent years and, therefore, can be helpful in diagnosing the disease.
\end{abstract}

Aims: The purpose of this study was to estimate the salivary amylase level in patients with types I and II diabetes mellitus and to correlate these findings with those of nondiabetic individuals in order to ascertain its value as a biochemical indicator for diagnosing and monitoring the patients.

Materials and methods: Three groups of patients were selected for the present study. Group A: 20 nondiabetic, healthy individuals; group B: 20 type I diabetes mellitus patients; group C: 20 type II diabetes mellitus patients. Fasting and postprandial unstimulated saliva samples were collected and subjected for analysis of salivary amylase. Estimation of salivary amylase was determined by direct substrate method.

Results: The mean fasting salivary amylase level for types I and II diabetic and nondiabetic individuals was 245.60, 239.10, and $149 \mathrm{U} / \mathrm{dL}$ respectively, whereas the mean postprandial salivary amylase was $257.35,246.15$, and $154.2 \mathrm{U} / \mathrm{dL}$ respectively. The mean value of variables was compared using Student's t test and one-way analysis of variance test.

Conclusion: The mean salivary amylase level was significantly increased in both types I and II diabetic individuals as compared with healthy nondiabetic subjects $(p<0.05)$. However, there was no significant difference in the mean of types I and II diabetic patients.

Keywords: Saliva, Salivary amylase, Type I diabetes mellitus, Type II diabetes mellitus.

${ }^{1}$ Professor, ${ }^{2}$ Reader, ${ }^{3}$ Professor and Head, ${ }^{4}$ Postgraduate Student

1,2Department of Oral and Maxillofacial Pathology and Microbiology, S. Nijalingappa Institute of Dental Sciences \& Research, Kalaburagi, Karnataka, India

${ }^{3}$ Department of Biochemistry, Mahadevappa Rampure Medical College, Kalaburagi, Karnataka, India

${ }^{4}$ Department of Oral and Maxillofacial Pathology, S. Nijalingappa Institute of Dental Sciences \& Research, Kalaburagi, Karnataka India

Corresponding Author: Shruti Singh, Postgraduate Student Department of Oral and Maxillofacial Pathology, S. Nijalingappa Institute of Dental Sciences \& Research, Kalaburagi, Karnataka India, Phone: +919740285424, e-mail:singhshruti1009@ gmail.com
How to cite this article: Satish BNVS, Kumar P, Avanti SM, Singh S. Salivary Amylase as Potential Biochemical Marker in Diabetes Mellitus. Int J Recent Surg Med Sci 2016;2(1):19-22.

Source of support: Nil

Conflict of interest: None

\section{INTRODUCTION}

Diabetes is a group of metabolic disorders characterized by hyperglycemia, resulting from defects in insulin secretion, insulin action, or both. Diabetes has emerged as a major health care problem in India. As per the 5th Atlas of Indian Diabetic Federation (IDF), there are currently 61.2 million diabetic individuals in India, and by the year 2030, it is set to cross 100 million marks. Chronic nature of diabetes mellitus entails a substantial decrease in quality of life and life expectancy. ${ }^{1,2}$

Monitoring blood glucose levels at frequent intervals causes discomfort for patients during the procedure of venipuncture and is the reason patients often avoid getting their blood glucose level monitored. In recent years, efforts have been made to replace blood test with other biological material samples. Saliva analysis is a relatively new tool for assessing biological markers. Saliva can provide a useful, noninvasive alternative to the collection of serum. It may prove to be a useful alternative especially when mass screening is to be done and when patient compliance can be a problem. ${ }^{3}$

Human salivary amylase ( $\alpha 1,4 \alpha$-D glucan, 4 gluconohydrolase) was first described by Leuchs in the year 1831. ${ }^{4}$ Human salivary amylase is a major component of human salivary secretions, responsible for hydrolysis of starch into small sugar molecules.

The purpose of our study was to correlate fasting and postprandial salivary amylase in types I and II diabetic individuals with normal healthy individuals and to establish the correlation of fasting and postprandial salivary amylase in types I and II diabetes.

\section{MATERIALS AND METHODS}

This was a prospective cohort study, which included a total of 60 subjects: twenty subjects of nondiabetic healthy individuals were taken as control group; 20 subjects diagnosed with type I diabetes mellitus; and 20 subjects diagnosed with type II diabetes mellitus. 
The study was conducted at the Basaveshwar Teaching \& General Hospital, Kalaburagi. We have included types I and II diabetes patients according to the American Diabetic Association 2014 guidelines and whose ages were 10 years and above of either gender. The control group included those who are healthy nondiabetic individuals and willing to participate in the study. Syndromic patients, pregnant females, and patients suffering with severe systemic illness as a manifestation of diabetes were excluded from the study.

Patients/legal guardians signed a clarified consent form to participate in the study. Patients demographic profile was noted. History in brief was taken; fasting and postprandial blood sugar along with glycosylated hemoglobin was taken; and current treatment received was recorded.

Blood glucose estimation was done by GOD-POD method (glucose is oxidized by glucose oxidase and converted to peroxidase). Unstimulated fasting and postprandial salivary samples were taken; the method involved for saliva collection was spitting method; and the time period of saliva collection was 5 minutes. All samples were collected between 8 and 11 A.M. to avoid any diurnal variation. Fasting salivary samples were collected in the morning after 8 hours of fasting, while postprandial samples were collected 2 hours after food intake. Salivary samples were collected in sterile containers by instructing the subjects to allow the saliva to collect in the mouth and then expectorate into the sterile containers.

The samples were immediately taken for biochemical analysis. Estimation of salivary amylase was done by direct substrate method (kinetic enzyme assay). The ability of $\alpha$-amylase to catalyze the hydrolysis of carbohydrates into small sugar molecules, such as maltose is the mainstay for salivary amylase estimation.

The collected saliva samples were diluted to 1 in 100 with deionized water. About $500 \mu \mathrm{L}$ of reagent (ready to use liquid reagent) and $10 \mu \mathrm{L}$ of saliva sample were added together and placed in a sample cap, and it was analyzed in a semiautomatic analyzer (Erba) (Figs 1A to C).

\section{RESULTS}

The present study comprised 28 males and 32 females. The mean age in type I diabetic patients was 31.85 years, type II was 55.7 years, and control healthy group was 51.5 years. Out of 20 type II diabetic patients, 13 were on oral hypoglycemic drugs, and 7 were using insulin as their treatment modality.

The mean fasting blood sugar was 195.3, 188.0, and $87.70 \mathrm{mg} / \mathrm{dL}$ in case of types I and II diabetic patients and control group respectively. The mean postprandial

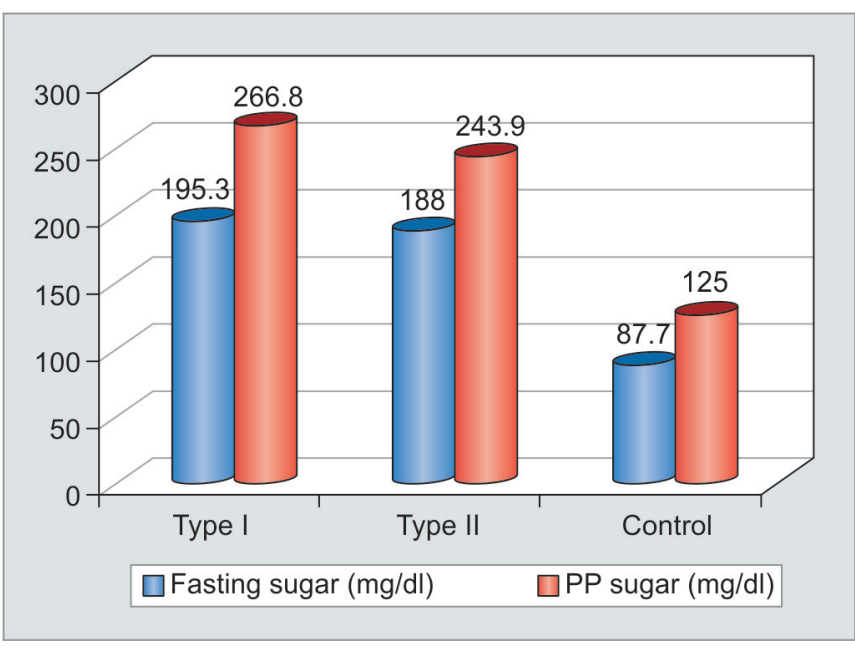

Graph 1: Chart depicting fasting and postprandial blood sugar levels in three groups

blood sugar level was $266.80 \mathrm{mg} / \mathrm{dL}$ in case of type I diabetic group, $243.90 \mathrm{mg} / \mathrm{dL}$ in case of type II diabetic group, and $125.0 \mathrm{mg} / \mathrm{dL}$ in case of control group (Graph 1).

The mean fasting salivary amylase was 245.60, 239.10, and $149 \mathrm{U} / \mathrm{dL}$ in type I diabetic group, type II diabetic group, and control healthy group respectively. The mean postprandial salivary amylase was $257.35 \mathrm{U} / \mathrm{dL}$ in type I diabetic group, $246.15 \mathrm{U} / \mathrm{dL}$ in type II diabetic group, and 154.2 U/dL in control group (Table 1).

The mean of glycosylated hemoglobin $\left(\mathrm{Hb}_{1} \mathrm{~A}_{\mathrm{c}}\right)$ was 7.075 in case of type I diabetic group, 7.175 in case of type II diabetic group, and 5.860 in case of control group.

The mean difference of fasting and postprandial salivary amylase of types I, II, and nondiabetic healthy individuals was compared using paired $t$ test and was found to have an insignificant difference $(p>0.05)$ (type I-p-value 0.453 , type II - p-value 0.197, and healthy control group - p-value 0.316) (Table 2).

Table 1: Mean value of fasting amylase and postprandial amylase in patients with types I and II diabetes mellitus

\begin{tabular}{llll}
\hline & & & $\begin{array}{l}\text { Standard } \\
\text { error mean }\end{array}$ \\
\hline Fasting amylase & Type I DM & $245.60 \pm 20.45$ & 4.565 \\
& Type II DM & $239.10 \pm 12.28$ & 2.730 \\
Postprandial & Type I DM & $257.35 \pm 19.39$ & 4.322 \\
amylase & Type II DM & $246.15 \pm 15.89$ & 3.544 \\
\hline
\end{tabular}

DM: diabetes mellitus

Table 2: Statistical observation of fasting and postprandial amylase and sugar

\begin{tabular}{lll}
\hline & Mean & $\begin{array}{l}\text { Standard error } \\
\text { mean }\end{array}$ \\
\hline Fasting amylase & $211.23 \pm 47.231$ & 6.097 \\
Postprandial amylase & $219.23 \pm 49.575$ & 6.400 \\
Fasting sugar & $157.00 \pm 54.140$ & 6.989 \\
Postprandial sugar & $211.90 \pm 72.587$ & 9.371 \\
\hline
\end{tabular}


The mean of fasting and postprandial salivary amylase was compared between types I and II diabetes patients using independent $t$-test and was found to be insignificant $(\mathrm{p}>0.05)$ (fasting salivary amylase $\mathrm{p}$-value 0.668 , postprandial salivary amylase $\mathrm{p}$-value 0.418) (Table 2).

However, the mean of fasting and postprandial salivary amylase when compared with nondiabetic healthy individuals (one-way analysis of variance test) resulted in a significant difference $(\mathrm{p}<0.05)$ (Table 2$)$.

\section{DISCUSSION}

Amylase is a digestive enzyme produced by salivary glands and pancreas that cleaves the glycosidic linkages in starch molecules to produce smaller saccharides, such as maltotriose, maltose, and small amounts of glucose. Salivary amylase can make up to $50 \%$ of total salivary protein in some individuals. ${ }^{5} \alpha$-Amylases are enzymes that hydrolyze starch into dextrins and monosaccharides composed of glucose units which causes hyperglycemia and development of diabetes mellitus. ${ }^{6}$

Altered expression of the amylase and cyclic AMP receptor in parotid glands of diabetic patients leads to changes in secretory proteins of human salivary glands, thus contributing to the altered salivary amylase level and oral diseases associated with diabetes. ${ }^{7}$ However, increased basement membrane permeability, associated with diabetes, can also be one of the possibilities for the increased leakage of protein amylase from salivary glands into their secretions in some patients. ${ }^{5,6}$

Dodds and Dodds ${ }^{8}$ noticed an elevated amylase activity with taste alterations in poorly controlled type II diabetes mellitus adults. Aydin, ${ }^{9}$ Pal et al, ${ }^{10}$ Meurman et al, ${ }^{11}$ Recio et $\mathrm{al}_{1}^{12} \mathrm{Hu}$ et $\mathrm{al},{ }_{1}^{13}$ and Chatterton et $\mathrm{al}^{14}$ reported that salivary $\alpha$-amylase values were higher in the diabetic group than in controls. Malathi et $\mathrm{al}^{15} \mathrm{did}$ a similar study on noninsulin-dependent diabetic individuals wherein she found elevated level of salivary amylase. López et a ${ }^{16}$ conducted a study and found that the level of salivary amylase in type I diabetic patients was elevated when compared with nondiabetic healthy individuals.

Carda et $\mathrm{al}^{17}$ found normal levels of salivary amylase activity in type II diabetic patients, whereas Tenovuo et $\mathrm{al}^{18}$ and Panchbhai et $\mathrm{al}^{19}$ in their respective studies observed lower levels of salivary amylase when compared with uncontrolled and controlled group of diabetic patients with healthy, nondiabetic patients. Yavuzyilmaz et $\mathrm{al}^{20}$ also found lower levels of salivary amylase in type II diabetics and suggested that this lower level of salivary amylase might be due to metabolic and hormonal influence. However, the level of amylase changes with oral hypoglycemic drugs and therapy. ${ }^{21}$
We observed raised level of salivary amylase in type I and type II diabetic groups. However, when fasting and postprandial salivary amylase level between types I and II diabetic groups was compared, the result was statistically insignificant. Ben-Aryeh et $\mathrm{al}^{22}$ conducted a study on 20 patients with insulin-dependent diabetes mellitus, 19 patients with noninsulin-dependent diabetes mellitus, and 20 subjects who are healthy nondiabetic individuals, and observed no difference in salivary amylase level among all the three groups.

Several authors have reported salivary amylase changes found in diabetic patients. The existing published articles have obtained variable correlation of salivary amylase in diabetic individuals. This variation could be attributed to diversity in selection criteria of samples and different study design. However, majority of the studies reported significantly higher values of salivary amylase in diabetic subjects when compared with healthy nondiabetic control individuals, which is also observed in our study. ${ }^{8-16}$

Interestingly, stress and salivary amylase have been studied vastly in the literature, and the consensus is that salivary amylase can be a potential biomarker for stress. ${ }^{23}$ We believe that stress could be the confounding factor for diabetes and raised serum amylase. Meurman et al ${ }^{11}$ in their study concluded that saliva secretion could be affected by autonomic nervous dysfunction in patients with noninsulin-dependent diabetics than in healthy control individuals.

\section{CONCLUSION}

Although no significant difference was found in salivary amylase level between types I and II diabetic patients, the

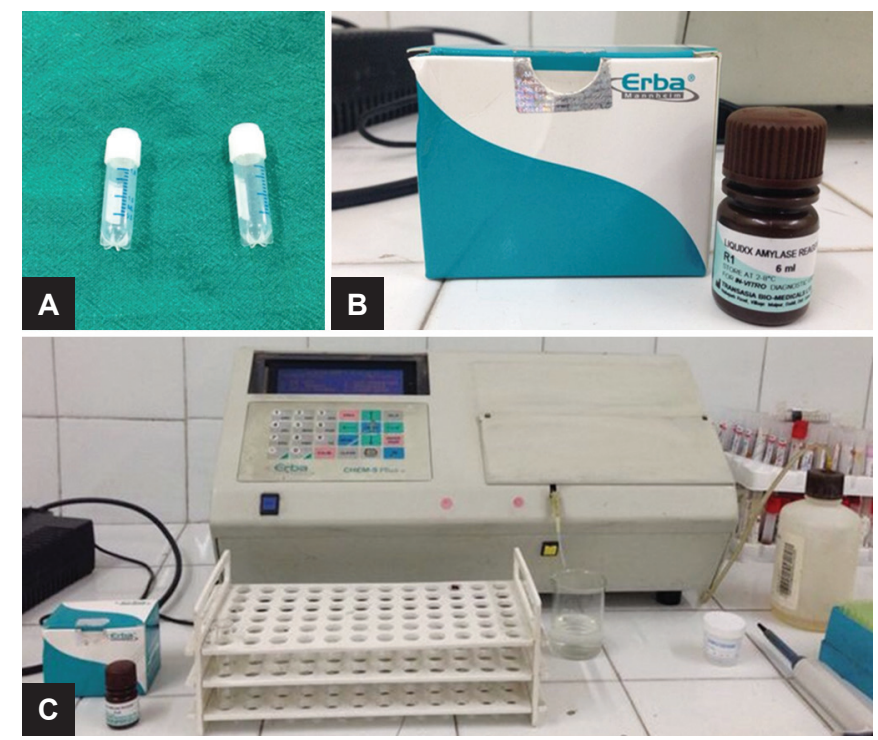

Figs 1A to C: (A) Fasting and postprandial salivary samples; (B) salivary amylase reagent (Erba); and (C) semiautomatic analyzer for salivary amylase estimation (Erba) 
mean salivary amylase level was significantly increased in both types I and II diabetic subjects as compared with healthy nondiabetic subjects $(p<0.05)$. The salivary amylase could be a potential biochemical marker in diabetes mellitus, but further study with larger sample size is needed.

\section{REFERENCES}

1. Stephens JM, Botteman MF, Hay JW. Economic impact of antidiabetic medications and glycemic control on managed care organizations: a review of the literature. J Manag Care Pharm 2006 Mar;12(2):130-142.

2. Coffey JT, Brandle M, Zhou H, Marriott D, Burke R, Tabaei BP, Engelgau MM, Kaplan RM, Herman WH. Valuing healthrelated quality of life in diabetes. Diabetes Care 2002 Dec;25(12):2238-2243.

3. Kaufman E, Lamster IB. The diagnostic applications of salivaa review. Crit Rev Oral Biol Med 2002;13(2):197-212.

4. Sampson EJ, Duncan PH, Fast DM, Whitner VS, McKneally SS, Baird MA, MacNeil ML, Bayse DD. Characterization and intermethod relation of materials containing purified pancreatic and salivary amylase. Clin Chem 1981 May;27(5):714-720.

5. Mandel ID. Sialochemistry in diseases and clinical situations affecting salivary glands. Crit Rev Clin Lab Sci 1980; 12(4):321-366.

6. Murrah VA, Crosson JT, Sauk JJ. Parotid gland basement membrane variation in diabetes mellitus. J Oral Pathol 1985 Mar;14(3):236-246.

7. Piras M, Hand AR, Mednieks MI, Piludu M. Amylase and cyclic AMP receptor protein expression in human diabetic parotid glands. J Oral Pathol Med 2010 Oct;39(9):715-721.

8. Dodds MW, Dodds AP. Effects of glycemic control on saliva flow rates and protein composition in non-insulin-dependent diabetes mellitus. Oral Surg Oral Med Oral Pathol Oral Radiol Endod 1997 Apr;83(4):465-470.

9. Aydin S. A comparison of ghrelin, glucose, alpha-amylase and protein levels in saliva from diabetics. J Biochem Mol Biol 2007 Jan 31;40(1):29-35.

10. Pal P, Desai NT, Kannan N, Masur VN, Daniel MJ, Bhatt N. Estimation of salivary glucose, salivary amylase, salivary total protein and periodontal microflora in diabetes mellitus. J Indian Dent Assoc 2003;74:143-149.

11. Meurman JH, Collin HL, Niskanen L, Töyry J, Alakuijala P, Keinänen S, Uusitupa M. Saliva in noninsulin-dependent diabetic patients and control subjects: the role of the autonomic nervous system. Oral Surg Oral Med Oral Pathol Oral Radiol Endod 1998 Jul;86(1):69-76.

12. Recio F, Villamil F, Recio C, Ferrer C. Early changes of urinary amylase isoenzymes in diabetes mellitus. Eur J Clin Chem Clin Biochem 1992 Oct;30(10):657-662.

13. Hu Y, Nakagawa $Y$, Purushotham KR, Humphreys-Beher MG. Functional changes in salivary glands of autoimmune disease-prone NOD mice. Am J Physiol 1992 Oct;263(4 Pt 1): E607-E614.

14. Chatterton RT Jr, Vogelsong KM, Lu Y, Ellman AB, Hudgens GA. Salivary $\alpha$-amylase as a measure of endogenous adrenergic activity. Clin Physiol 1996 Jul;16(4):433-448.

15. Malathi L, Masthan KM, Balachander N, Babu NA, Rajesh E. Estimation of salivary amylase in diabetic patients and saliva as a diagnostic tool in early diabetic patients. J Clin Diagn Res 2013Nov;7(11):2634-2636.

16. López ME, Colloca ME, Páez RG, Schallmach JN, Koss MA, Chervonagura A. Salivary characteristics of diabetic children. Braz Dent J 2003;14(1):26-31.

17. Carda C, Mosquera Lloreda N, Salom L, Gomez de Ferraris ME, Peydró A. Structural and functional salivary disorders in type 2 diabetic patients. Med Oral Patol Oral Cir Bucal 2006 Jul 1;11(4):E309-E314.

18. Tenovuo J, Lehtonen OP, Vkari J, Larjava H, Vilja P, Tuohimaa P. Immunoglobulins and innate antimicrobial factors in whole saliva of patients with insulin-dependent diabetes mellitus. J Dent Res1986 Jan;65(1):62-66.

19. Panchbhai AS, Degwekar SS, Bhowte RR. Estimation of salivary glucose, salivary amylase, salivary total protein and salivary flow rate in diabetics in India. J Oral Sci 2010 Sep;52(3):359-368.

20. Yavuzyilmaz E, Yumak Ö, Akdoanli T, Yamalik N, Özer $\mathrm{N}$, Ersoy F. The alterations of whole saliva constituents in patients with diabetes mellitus. Aust Dent J1996 Jun;41(3): 193-197.

21. Shankaraiah P, Reddy YN. $\alpha$-Amylase expressions in Indian type-2 diabetic patients. J Med Sci 2011;11(7):280-284.

22. Ben-Aryeh H, Serouya R, Kanter Y, Szargel R, Laufer D. Oral health and salivary composition in diabetic patients. J Diabetes Complications 1993 Jan-Mar;7(1):57-62.

23. Nater UM, Rohleder N. Salivary alpha-amylase as a noninvasive biomarker for the sympathetic nervous system: current state of research. Psychoneuroendocrinology 2009 May;34(4):486-496. 